\title{
Cesarean Section in Low Birth Weight Babies: An Original Research
}

\author{
Hara Prasad Pattanaik ${ }^{1}$, Mrutyunjay Mohapatra ${ }^{1}$, Sasmita Parida $^{2}$ \\ ${ }^{1}$ Consultant Gynecologist \& Obstetrician, Cuttack, Odisha, \\ ${ }^{3}$ Prof \& HOD, Department o Radiodiagnosis, SCB Medical college, Cuttack, Odisha
}

\begin{abstract}
The high prevalence of high-risk pregnancies, which can lead to premature delivery, contributes to an increase in the rates of preterm and low-birth weight (LBW) infants, with an increase in the number of cesarean deliveries. This study was done to access maternal variables and their associations with cesarean deliveries of LBW newborns. A retrospective study was conducted by reviewing the medical records of pregnant women who underwent cesarean sections for the delivery of LBW infants (weight, $\geq 1500$ and 35 weeks at delivery, and $50.8 \%$ attended less than eight prenatal consultations. Hypertensive syndrome $(23.8 \%)$ was the main indication for cesarean delivery. Among the newborns, 58.3\% had an Apgar score of 7 in the first minute of life, $79.3 \%$ had a score of 9 in the fifth minute of life, and $54.3 \%$ were females. Conclusions: Several maternal variables such as primiparity, education level, number of prenatal consultations, and presence of maternal hypertensive syndrome had a statistically significant association with the occurrence of cesarean sections for the delivery of LBW infants.
\end{abstract}

Keywords: High-Risk Pregnancy; Cesarean Section; Low-Birth Weight Newborns; Prenatal Care; Gestational Age; Hypertensive Syndrome.

\section{Introduction}

In a developing country like ours the increased incidence of low birth weight babies either due to preterm delivery or IUGR is a major problem so far as perinatal outcome is concerned. The proven contention over the last few years that rise in the rate of caesarean section has dramatically reduced the perinatal mortality and morbidity to a significant extent. Though it is difficult to prove the causal relationship between these two events, the consensus of opinion about recognition of the foetus in utero as a second patient and its right for survival beginning from the time of fertilisation has revolutionized the approach for the appropriate mode of termination when one considers quality maternity and child health services in the present day obstetric practice. Though

\section{Corresponding Author:}

Dr. Hara Prasad Pattanaik

Consultant Gynecologist \& Obstetrician, Cuttack, Odisha birth weight is one of the most important consideration as regards the mode of delivery, in broader perspective, the Obstetrician encounters two main Intricate aspects while encountering cases of low birth weight; preterm and growth retarded. Apart from the fact that Improved neonatal care In the present era has revolutionized the management of these groups. Regarding birth weight, the World Health Organization (WHO) defines NBs with low birth weight (LBW) as those with birth weight of $<2500 \mathrm{~g}$ and $\geq 1500 \mathrm{~g}$, regardless of gestational age (GA). Birth weight is the factor that most influences infant survival, and because it represents only one final measurement, anticipating its diagnosis can contribute to decreased morbidity and mortality.

In these High tisk pregnancies, still the decision of the gynecologist in regards to the mode of delivery is of vital concern which affects the perinatal outcome to a great extent. Epidemiological studies revealed that LBW is a risk factor for increased neonatal morbidity and mortality and for the later development of obesity, diabetes mellitus, and particularly cardiovascular illnesses ${ }^{1}$. 
On the otherhand, the management of growth retarded babies in utero is also very delicate as the correct formulation of the route of delivery is an essential prerequisite for subsequent intensive care reflecting in increase in both short term and long term survival. Viewed in these controversial contexts in mind this piece of work has been undertaken in the department of Obstetricis and Gynaecology where various perinatal factors in the low birth weight babies delivered by caesarean section are correlated with a control group of low birth weight babies born via natural is in order to find out the positive value of mode of delivery to an optimum perinatal outcome ${ }^{2}$.

The present study was carried out in the Department of Obstetrics and Gynaecology of S.C,.B. Medical College, Cuttack in Pregnant mothers having low birth weight babies (weighing less than 2500g) were scrutinized from amongst antenatal diagnosis.

A sum total of two hundred cases of pregnancies having low birth weight babies undergoing caesarean section served as study series where as hundred cases, having low birth weight babies delivering vaginally which were selected at random, taken as control group

Exclusion criteria in our study include Multifoetal pregnancy and Intra uterine deaths. A detailed history of the patients with special reference to age, parity. socio-economic status, present obstetric and medical complications were taken. An effort was made to ascertain the gestational age with accuracy as far as possible. Thorough intrapartum events were looked into and a meticulous search was made as regards the neonatal outcome with reference to details of morbidity as well as mortality pattern; so as to have a positive correlation with the study as well as control group in order to find out the role of caesarean section in low birth weight babies.

This study was made on the role of caesarean section in 200 cases of low birth weight babies and were compared to100 vaginal deliveries as control in closely matched birth aspects.

\section{Results}

The following Observations were made on various weights of cases and controls.

Highest number of low birth weight caesarean sections has occurred in 21-25 years age group. In vaginal delivery cases it was also highest (51\%). Highest number of low birth weight deliveries is in low socioeconomic status (68\% in both). We have taken monthly income of less than Rs.1000.00 as low, Rs.1000-3000/as middle and more than Rs. 3000.00 per month as upper socio-economic group. $61 \%$ of low birth weight caesarean cases were unbooked compared to $47 \%$ of low birth weight vaginal deliveries. Conversely only $39 \%$ of study were booked compared to $53 \%$ of controls.

Both in study and control series highest number of low birth weight deliveries took place in primi $(49.5 \%$ and $50 \%$ respectively). Highest number of deliveries took place in the gestational age group of 37-38 weeks both in study and control series (33\% and $28 \%$ respectively) followed closely by the gestational age of 35-36 weeks. In the gestational age of $29-34$ weeks $19 \%$ and $21 \%$ deliveries took places in each group respectively (14 in $29-30$ weeks $3.5 \%$ in $31-32$ weeks and $14.5 \%$ in $33-34$ weeks gestational in study group and $3 \%, 4 \%$ and $14 \%$ in control group respectively).

This study shows relevant maternal complications during Pregnancy in both groups. Maternal complications were not detected in $77.5 \%$ case in caesarean group and $71 \%$ in vaginal delivery group. Pregnancy induced hypertension contributed to $10.5 \%$ and $12 \%$ respectively in study and control group and antepartum haemorrhage was found in $7 \%$ and $8 \%$ respectively. Among the maternal indications placenta praevia topped the list (16.5\%) with premature rupture of membrane (14.5\%), PET/Eclampsia (10.5\%) following it. Among foetal indications foetal distress $(27 \%)$ was the commonest followed by IUGR $(3.5 \%)$ and breech' presentation $(13 \%)$ of cases.

In many cases operation has been done for more than one indication. $79 \%$ had spountaneous onset of labour where as $21 \%$ cases were induced. 29 cases had normal deliveries, 41 cases had episiotomy. Forceps was applied in 22 cases and 8 cases had Assisted breech delivery. This study shows distribution of cases in different birth weight group of newborn infants. In study group highest number of infants $(48.5 \%)$ were delivered with birthweight of 2000-2249 grams. Similarly in vaginal delivery group $37(37 \%)$ infants were in same birth weight group. In the study group $50 \%$ of infants had no morbidity. In the rest Asphyxia was found in $43 \%$ and hypothermia in $31.5 \%$ of infants. In the vaginal delivery group $35.3 \%$ of babies had no morbidity while $43.7 \%$ suffered from asphyxia and $31.7 \%$ from hypothermia. 


\section{Discussion}

The present study comprised of two hundred cases of low birth weight babies delivered by caesarean section while one hundred cases of low birth weight babies born via naturalis served as control.

The cases were selected from amongst the emergency and booked admissions to the department. We excluded the cases having multifoetal pregnancy and intrauterine foetal death. Relevant history noted and thorough examination done. Nature of deliveries were studied in these low birth weight cases. On delivery the babies were resuscitated and Apgar score at birth \& after 5 minutes were noted. The neonatal mortality and morbidity pattern compared.

Out of a sum total of 918 caesarean sections during the study period there were 200 cases of low birth weight babies, the incidence being $21.8 \%$ (Hospital data), the figure close to that reported by Rege et al (1987) (27\%).

Analysis of age distribution of cases both in the study as well as control series (Table-I) closely demonstrates an almost similar percentage of cases in each age group, where maximum number of cases are observed between the age range $21-25$ years $(50 \%$ and $51 \%$ in study and control respectively). This is a justifiable fact because second and third decade of life is the period of maximun reproductive potential and hence present to the institution more commonly for their confinements. The frequency of occurrance of low birth weight babies is commonly encountered amongst patients belonging to low socioeconomic status ${ }^{3-5}$.

Distribution of cases according to gestational age as reported by Jayant et al (1987) however revealed 31.8\% in $37-38$ weeks, $26.4 \%$ in $39-40$ weeks and $19.7 \%$ in 35-36 weeks. The association of relevant maternal complication in our series in the form of pregnancy induced hypertension, Antepartum haemorrhage, Diabetes mellitus, cardiac disease and anemia. Our observation closely tallies with esslein et al (1979) who reported a wide ranging associated with Preterm labour (19.1\%), PROM (38.1\%) mia (19.1\%), Abruptio placentae $(7.1 \%)$ and placental gestation $(7.1 \%)^{6,7}$.

The nature of caesarean section in study group reveals relatively small percent of cases where elective caesarean section has been contemplated (8\%) in contrast to emergency caesarean. Our finding did not corroborate with those of Pinion in $92 \%$ of cases. The different indications for caesarean section in which majority of cases required intervention because of foetal distress (28\%). However section was performed in $16.5 \%$ for placenta praevia, $10.5 \%$ for preeclampsia/ eclampsia, $14.5 \%$ for PROM $12.5 \%$ for breech and $13.5 \%$ for IUGR.

Pinion et al in contrast recorded that caesarean section done in $6.5 \%$ of cases for foetal distress which shows a significantly reduced figure in comparision to our series. The other indications of their series in nearly similar to that of ours. This could be because of the fact that more number of cases of our series probably had intrauterine growth retardation in contrast to a prepondorance of preterm caesarean section in Pinion's series $^{8,9}$.

In a study of 91 cases by Jayant et al (1987) the common maternal indication for low birth weight caesarean section were feto-pelvic disproportion $11(12 \%)$ cases, previous caesarean section $11(12 \%)$ cases, pre-eclampsia/eclampsia $10 \quad(10.9 \%)$ cases, mechanical dystocia $7(7.6 \%)$ cases. Amongst foetal indications, foetal distress accounted for $20.8 \%$ of cases, other malpresentations $7.6 \%$, and breech $5.4 \%$ of cases. Indications of above series correlates to our study.

Haesslein et al (1979) in a study of 30 cases found that the indication of low birth weight caesarean section was mostly due to breech presentation (36.3\%) and pregnancy induced hypertension(33.3\%).

In the study by Barret et al (1983) breech (45.6\%) severe PET (21.7\%), foetal distress (10.8\%) and IUGR $(8.6 \%)$ were the common indications for low birth weight caesarean section. Indications of operations in our study do not correlate to that of Haesslein et al and Barret et al as their studies are mainly on lower birth weight groups than those of ours. In study group, $48.5 \%$ had a birth weight of 2000-2249g where as in the same range $37 \%$ were found in the control series. In birth weight below $1500 \mathrm{~g}, 3.5 \%$ of cases were observed in study in contrast to 74 in control group. The distribution pattern in relation to birth weight follows an almost similar pattern in both the study and control series, the findings being compatible to those of Jayant et al (1987) and Pinion et al (1988).

Correlation of birth weight with gestational age reveals that in birth weight group more than $2000 \mathrm{~g}$ majority of cases are encountered at a gestational age beyond 35 weeks both the study as well as control group. 
Below the gestational age of 30 weeks, 2 cases are seen in the weight range of $1000-1499 \mathrm{~g}$ while not a single case was recorded in the study group in the same weight group. Out of the cases delivered by caesarean section on babies weighing between 1000-1499g majority (42.8\%) are encountered in 31-32 weeks range.

Rege et al (1987) observed in their series that the highest section rate in 1000-2000g weight group was at 37-38 weeks of gestation indicating the preponderance of growth retardation. Overall section rate before 37 weeks were $12 \%$ in Pinion et al (1988) and $21.7 \%$ in Kafka et al (1969) series.

From our study it could be inferred that the low birth weight babies are in a compromised state at birth and hence an optimum level of neonatal resuscitative measure is mandatory both in the study and control series $^{10}$.

Our study shows the neonatal morbidity pattern in both study and control group, which reveals that the overall neonatal morbidity is significantly more (64.7\%) amongst babies born vaginally in comparision to a morbidity figure of $50 \%$ in study series. This shows a probable relationship between morbidity and route of delivery. Asphyxia by far accounted for maximum number of cases both in study and control series (434 and $43.7 \%$ ).

Analysing The morbidities in different weight groups, it is evident that in 1000-1499g birth weight group all the babies (both groups) had neonatal complications. But the caesarean babis had faired better than the control group percentage wise. $71.4 \%$ and $87.5 \%$ in study and control series respectively ${ }^{11}$.

Asphyxia remained as the dominant factor i.e. In 1500-1999gm weight group the caesarean babies had less perinatal sufferings than the control group (percentagewise), majority being attributted to asphyxia (70\%, vs 93.7\%). In higher birth weight groups of 2000$2249 \mathrm{~g}$ and $2250-2499 \mathrm{~g}$ the neonatal morbidities were found in similar proportions in both series. Asphyxia remained as the main complication but the percentage dropped down as birth weight improved $(42.2 \%$ and $21.2 \%$ in study and $48.6 \%$ and $21.8 \%$ in control groups). Our observation closely corroborates to those of Pinion et al (1988), Rege et al (1987), Haesslein et al (1979) and Shennan et al $(1980)^{12}$.

\section{Conclusion}

As regards perinatal mortality in our series it is evident that the overall perinatal mortality is significantly higher in cases born by vaginal route in contrast to those where section has been contemplated (19\% and $14.5 \%)$. Another important point of concern is that about $36.8 \%$ of cases had fresh still birth in comparision to $63.2 \%$ of cases having neonatal deaths amongst vaginally delivered babies.

Ethical Permission: Obtained

Conflict of Interests: None

Funding: None

\section{References}

1. Reis ZS, Lage EM, Aguiar RA, Gaspar JS, Vitral GL, Machado EG. Associação entre risco gestacional e tipo de parto com as repercussões maternas e neonatais. Rev Bras Ginecol Obstet. 2014; 36: 65-71.

2. Delnord M, Blondel B, Zeitlin J. What contributes to disparities in the preterm birth rate in European countries? Curr Opin Obstet Gynecol. 2015; 27: 133-142.

3. Brasil. Ministério da Saúde. Secretaria de Políticas de Saúde. Área Técnica da Saúde da Mulher. Parto, aborto e puerpério: assistência humanizada à mulher. Brasília (DF): Ministério da Saúde; 2003.

4. Marcondes WB. A convergência de referências na promoção da saúde. Saúde Soc. 2004; 13: 5-13.

5. Leal MD, Gama SG, Cunha CB. Racial, sociodemographic, and prenatal and childbirth care inequalities in Brazil, 1999-2001. Rev Saúde Pública. 2005; 39: 100-107.

6. Costa HF, Costa CF, Costa LO. Idade materna como fator de risco para a hipertensão induzida pela gravidez: análise multivariada. Rev Bras Ginecol Obstet. 2003; 25: 631-635.

7. Haidar FH, Oliveira UF, Nascimento LF. Escolaridade materna: correlação com os indicadores obstétricos. Cad Saúde Pública. 2001; 17: 1025-1029.

8. Santini de Almeida MA. Gravidez adolescente: a diversidade das situações. Rev Bras Estud Popul. 2002; 19: 197-207. 
9. Shah MK, Gee RE, Theall KP. Partner support and impact on birth outcomes among teen pregnancies in the United States. J Pediatr Adolesc Gynecol. 2014; 27: 14-19.

10. Li YM, Chang TK. Maternal demographic and psychosocial factors associated with low birth weight in eastern Taiwan. Kaohsiung J Med Sci. 2005; $21:$ 502-510.
11. Arruda DC, Marcon SS. A família em expansão: experienciando intercorrências na gestação e no parto do bebê prematuro com muito baixo peso. Texto Contexto Enferm. 2007; 16: 120-128.

12. Brasil. Ministério da Saúde. Conselho Nacional de Saúde. Resolução n. 466, de 12 dezembro 2012. Dispõe sobre as diretrizes e normas regulamentadoras de pesquisa envolvendo seres humanos. Diário Oficial da União, Brasília (DF); 2013; 1: 59. 